\title{
Research on the Validity of China's Stock Market Based on Random Walk Test
}

\author{
Fengrui Liu ${ }^{\mathrm{a}}$, Xiaohui Hu ${ }^{\mathrm{b}}$, Fuchang $\mathrm{Li}^{\mathrm{c}^{*}}$ \\ School of Economics \& Management \\ Yunnan Normal University \\ Kunming, China \\ 921754310@qq.com ${ }^{\mathrm{a}}$,75042344@qq.com ${ }^{\mathrm{b}}$,24695192@qq.com ${ }^{\mathrm{c}^{*}}$
}

\begin{abstract}
China's stock market has been in existence for nearly 30 years since its inception, and there have been many problems at the same time of rapid development, such as frequent skyrocketing and imperfect regulatory systems. The issue of stock market validity is one of the focuses of scholars. We use the random walk test to analyze the 6704 trading days of the Shanghai Composite Index from December 17, 1990 to May 18, 2018 and SZSE Component Index for 6617 trading days for the holidays and non-trading days from April 3, 1991 to May 18, 2018.It is concluded that the initial stage of China's stock market is an ineffective market, and then gradually shifts to a weak effective market. The current market situation can be roughly identified as a weak-form market efficiency.
\end{abstract}

Keywords-Market efficiency; Weak-Form market efficiency; Random walk test; First-order autoregressive

\section{INTRODUCTION}

China's stock market has been developing rapidly since the opening of Shanghai Stock Exchange in December 1990 and the opening of the Shenzhen Stock Exchange in April 1991 for nearly 30 years. China's stock market has developed rapidly, but during the period it has experienced many ups and downs. In practice, there have been many institutional problems. The effectiveness of the stock market has become a concern of scholars. A considerable number of scholars have studied the effectiveness of China's stock market. Most of the researches on the early stage of China's stock market development believe that China's stock market has not reached a weak-form market efficiency. With the further development of China's stock market, the research on market effectiveness has more data, and more research methods and advanced research tools. The test method based on the market efficiency hypothesis has been applied to a large number of scholars, but the conclusions are divided. Some scholars believe that China's stock market has reached a weak-form market efficiency, while other scholars believe that it has not been reached.

Based on the previous research, this paper analyzes the Shanghai Composite Index and the Shenzhen Composite Index by random walk test. It believes that China's stock market is an ineffective market at the beginning of its establishment, and then gradually shifts to a weak effective market. The current market situation can be approximated as weak-form market efficiency.

\section{RELATED THEORY}

Fama proposes a valid market hypothesis that investors' gains can only be matched to the risks they bear, and excess returns that are higher than risk compensation do not exist. [1] There are two important prerequisites for market effectiveness: 1. Investors can process information and analyze information, and make correct judgments on the price of securities based on information; 2. Information that can affect the movement of securities prices is free flowing. An effective market can fully reflect all available information. [2] In the case of the establishment of the efficient market hypothesis, the society is full of information exchange, and specific information can be quickly obtained by investors in the stock market, and there is no information asymmetry. Competition in the stock market drives the price of the stock to fully reflect the information, and the investor's rate of return is the average stock market return. An effective market needs to have four characteristics: 1 . effective information disclosure; 2. effective information acquisition; 3. effective information judgment; 4. effective investment behavior. According to the difference in the number of the above conditions, the effective market is divided into a weak-form market efficiency, a semi-strong-form market efficiency and a strong-form market efficiency. The weak-form market efficiency satisfies the conditions of 1 and 4 . In this form, information cannot be fully disclosed and cannot be fully interpreted. The information implied in the previous transaction price and trading volume has been fully reflected in the securities price, and investors cannot obtain excess profits by analyzing the previous stock price movements. Excess profits can only be obtained by analyzing insider information other than historical price information. The semi-strong-form market efficiency satisfies the conditions of 2,3 , and 4 , in which the complete disclosure of information is hindered. Similarly, using insider information can achieve excess profits. The published information is meaningless for the acquisition of excess profits. A strong-form market efficiency satisfies all four conditions. All public information and insider information can be quickly and timely reflected in the stock price. Anyone can only get the average income and there is no excess profit. The three forms are interconnected, but the number of conditions met is different. The weak-form market efficiency is the basis of the effective market theory. It is even less likely to satisfy the stronger market efficiency conditions without satisfying the weak-form market efficiency conditions. Therefore, empirical research mostly focuses on the testing of weak-form market efficiency.[3][4][5] 


\section{THE SIGNIFICANCE OF THE RESEARCH ON THE EFFECTIVENESS OF STOCK MARKET}

\section{A. Provide a Theoretical Basis for Policy Development}

The information integrity of stocks, the way of price changes and timeliness are important factors affecting the distribution and adjustment efficiency of funds in the securities market. Only when stock prices are fair and reasonable can the funds be rationally allocated between producers and investors. The study of market effectiveness can provide theoretical basis and support for the development of policies by the China Securities Regulatory Commission (CSRC) and other departments. The compulsory system of information disclosure can obtain theoretical basis from the effective market theory. The study of effective market can also improve the efficiency development direction of China's stock market.

\section{B. Guiding Investors' Investment Behavior}

If the market is at least weak-form market efficiency, even professional investors cannot beat the market, and cannot obtain excess returns through historical data analysis, negating the investment philosophy of active management. Conversely, if the stock market is ineffective, investors and investment institutions can construct a portfolio to obtain excess returns by analyzing historical data. Therefore, the issue of the effectiveness of China's stock market can guide investors' behavior and make a significant impact on guiding investment.

\section{Standardize the Management and Operation of Listed Companies}

According to the efficient market hypothesis, the higher the efficiency of the stock market (closer to the strong-form market efficiency), the more quickly the information related to the listed company will be known to investors and integrated into the stock price. This forced the senior management of the listed company to operate with the goal of maximizing the interests of shareholders, standardizing its own management, management, and governance structure issues, and starting from improving the operating performance of listed companies. Instead of misleading investors by improper means such as controlling information, use false information to speculate on stock prices. When the stock market is ineffective, the senior management of the listed company may control the stock price by seeking improper means such as information asymmetry. Choosing an accounting method that is beneficial to the rise in stock prices to hide unfavorable information does not really care about the operation and management of listed companies and damage the long-term interests of shareholders. Therefore, the study of the effectiveness of the stock market is conducive to standardizing the business behavior of listed companies in the capital market and promoting the healthy growth of China's stock market and economy.

\section{AN EMPIRICAL STUDY ON THE WEAK-FORM MARKET EFFICIENCY OF CHINA'S STOCK MARKET}

\section{A. Data}

The data studied in this paper is based on the withdrawal of the Shanghai Composite Index on the 6704 trading days of the holiday and non-trading days from December 29, 1990 to May 18, 2018 and the withdrawal of the Shanghai Composite Index on the 6617 trading days of the holiday and non-trading days from April 3, 1991 to May 18, 2018. All data we used are from the Wind Financial Database. The descriptive statistics of the Shanghai Composite Index and its daily yield is shown in Table I as follows.

TABLE I. DESCRIPTIVE STATISTICS OF THE SHANGHAI COMPOSITE INDEX AND ITS DAILY YIELD.

\begin{tabular}{|l|l|l|l|l|l|}
\hline \multicolumn{1}{|c|}{ Variable } & $\begin{array}{c}\text { Sample } \\
\text { size }\end{array}$ & \multicolumn{1}{|c|}{ Mean } & $\begin{array}{c}\text { Standard } \\
\text { deviation }\end{array}$ & Minimum & $\begin{array}{c}\text { Maximu } \\
\text { m }\end{array}$ \\
\hline $\begin{array}{l}\text { Shanghai } \\
\text { Composite } \\
\text { Index }\end{array}$ & 6703 & 1879.393 & 1077.611 & 99.98 & 6092.057 \\
\hline Daily income & 6702 & 0.0797538 & 2.522338 & -16.39 & 105.27 \\
\hline
\end{tabular}

And the descriptive statistics of the Shenzhen Composite Index and its daily yield is shown in Table II as follows.

TABLE II. DESCRIPTIVE STATISTICS OF THE SHENZHEN COMPOSITE INDEX AND ITS DAILY YIELD

\begin{tabular}{|l|l|l|l|l|l|}
\hline \multicolumn{1}{|c|}{ Variable } & $\begin{array}{c}\text { Sample } \\
\text { size }\end{array}$ & \multicolumn{1}{|c|}{ Mean } & $\begin{array}{c}\text { Standard } \\
\text { deviation }\end{array}$ & Minimum & $\begin{array}{c}\text { Maximu } \\
\text { m }\end{array}$ \\
\hline $\begin{array}{l}\text { Shanghai } \\
\text { Composite } \\
\text { Index }\end{array}$ & 6615 & 746.499 & 586.1622 & 45.66 & 3140.662 \\
\hline Daily income & 6615 & 0.0683194 & 2.219528 & -20.8327 & 31.2862 \\
\hline
\end{tabular}

The time series line chart of the Shanghai Composite Index is shown in Fig. 1 below.

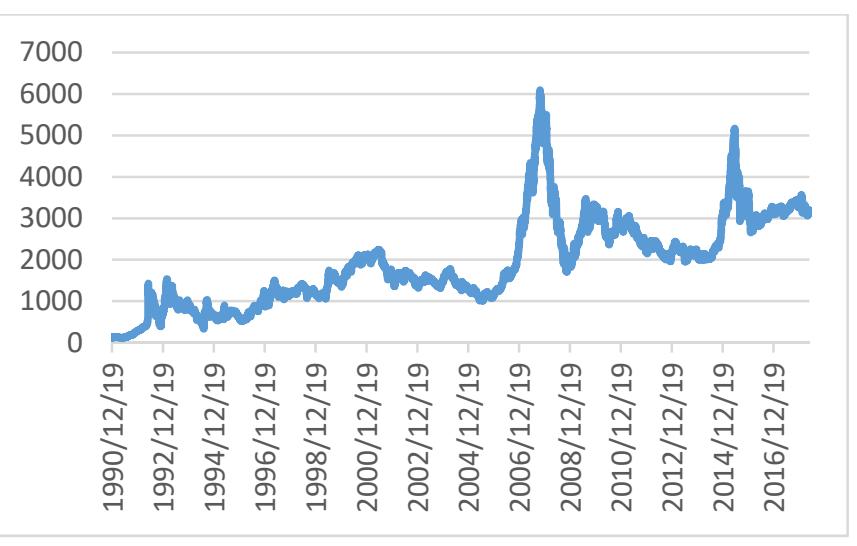

Fig. 1. Shanghai Composite Index time series chart

The time series line chart of the Shenzhen Composite Index is shown in Fig. 2 below. 


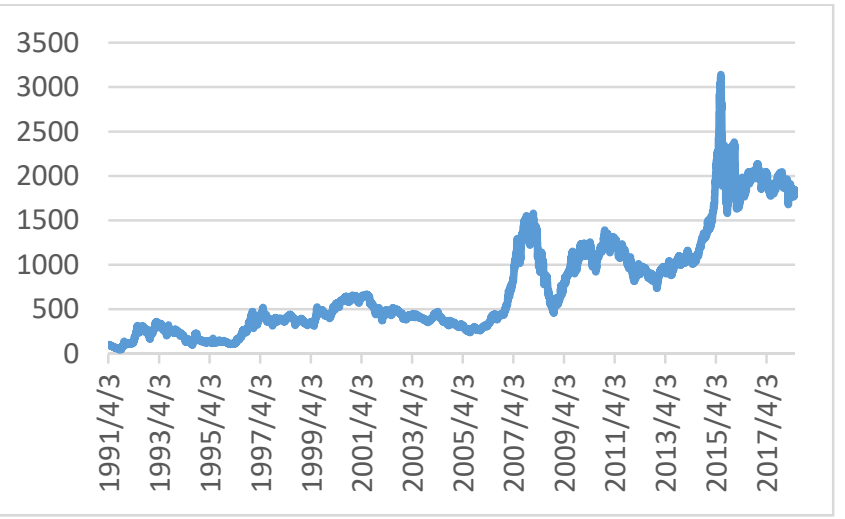

Fig. 2. Shenzhen Composite Index time series chart

\section{B. Guiding Investors' Investment Behavior}

When stock prices are subject to random walks, the trajectory of the price at any time cannot be predicted by analyzing the previous data, there is no clear upward trend or downward trend, and there is no tendency to return to a certain value. Fama gives an efficient market hypothesis model as we can seen in (1):

$$
E\left(P_{i, t+1} \mid \Omega_{t}\right)=\left[1+E\left(r_{i, t+1} \mid \Omega_{t}\right)\right] P_{i, t}
$$

Among them, $P_{i, t+1}$ is the price of securities $i$ at time $t$, $\Omega_{t}$ is the information set at time $t, r_{i, t}$ is the yield of securities $i$ at time $t, r_{i, t+1}=\frac{P_{i, t+1}-P_{i . t}}{P_{i, t}}$. In the case of a market effective, investors cannot obtain excess profits by using the known information set $\Omega_{t}$, and the expectation of excess profit is $0, E\left(r_{t+1} \mid \Omega_{t}\right)=0$. Using the existing historical information set $\Omega_{t}$ to estimate the future price $P_{t+1}$ of the security, the result can only converge to the current price, the current price already contains all the historical information.

The random walk model assumes that the amount of change in the price series is independently and identically distributed, and its mathematical expression can be expressed as follows (2):

$$
f\left(P_{i, t+1} \mid \Omega_{t}\right)=f\left(P_{i, t+1}\right)
$$

The general expression of the random walk model is (3):

$$
P_{t}=P_{t-1}+\varepsilon
$$

Then construct a simple first-order autoregressive model with the expression as (4):

$$
P_{t}=\beta_{0}+\beta_{1} P_{t-1}+\varepsilon_{t}
$$

Among them, the stock price $P_{t}$ is taken back by the Shanghai Composite Index and the Shenzhen Composite Index respectively. When the market is weak, $\varepsilon_{t}$ is white noise, $\hat{\beta}_{0}=0, \quad \hat{\beta}_{1}=1,\left\{\varepsilon_{t}\right\}_{\text {iid }} \sim \mathrm{N}\left(0, \sigma^{2}\right) \quad \sigma^{2}<+\infty$.

The simple first-order autoregressive results using the Shanghai Composite Index are as follows (5):

$$
\begin{gathered}
P_{t}=0.9991666 P_{t-1}+2.042724 \\
(0.000) \quad(0.045) \\
t=2135.49 \quad t=2.00 \\
N=6702 \quad R^{2}=0.9985 \quad \bar{R}^{2}=0.9985
\end{gathered}
$$

Then, based on the regression results, it is checked whether the coefficient is significant to 1 and whether the constant term is significantly $0 .(6)$ is the result of the test.

$$
\begin{array}{cc}
H_{0}: \hat{\beta}_{1}=1 & P=0.0749 \\
H_{0}: \hat{\beta}_{0}=0 & P=0.0454
\end{array}
$$

The test results all accepted the hypothesis with a lower p-value, that is, the change of the Shanghai Composite Index satisfies the random walk hypothesis. However, due to the low p-value, it is impossible to significantly prove that the change of the Shanghai Composite Index is a random walk.

The simple first-order autoregressive results using the Shenzhen Composite Index are as follows (7):

$$
\begin{gathered}
P_{t}=0.99968 P_{t-1}+0.4992923 \\
\quad(0.000) \quad(0.169) \\
t=2615.59 \quad t=1.38 \\
N=6614 \quad R^{2}=0.9990 \quad \bar{R}^{2}=0.9990
\end{gathered}
$$

Then, based on the regression results, it is checked whether the coefficient is significant to 1 and whether the constant term is significantly $0 .(8)$ is the result of the test.

$$
H_{0}: \hat{\beta}_{1}=1 \quad P=0.4025
$$

$$
H_{0}: \hat{\beta}_{0}=0 \quad P=0.1687
$$


The p-value of the test results is larger than that of the Shanghai Composite Index. It can be considered that the change of the SZSE is similar to the random walk.

\section{CONCLUSION AND OUTLOOK}

The last section of the analysis roughly estimates the effectiveness of the two stock markets in China, and believes that the stock price changes in the two cities are subject to random walks, but not significant. Since the random walk test method is derived from the research of mature stock market, the data studied in this paper starts from the trading day of the two cities, and the invalidity in the early stage of development will affect the validity test of the whole period. For China, effective market research is conducive to the development of financial theory and investment theory in line with the reality of China's stock market. China's stock market has its own unique characteristics, and there are differences between the western stock market, which requires a unique theory and theoretical innovation. Therefore, in future researches, we should focus on developing an effective market theory that conforms to the actual situation of China's stock market, and further verify the validity of China's stock market by correcting the model assumptions, frameworks and parameter settings of Western effective market theory. After making reliable conclusions about the efficiency of China's stock market, financial theory and investment theory in line with China's reality can truly serve economic construction and guide investment time and long-term development of the stock market.

\section{ACKNOWLEDGMENT}

The authors greatly appreciate the anonymous referees and the associate editor for their very valuable and helpful suggestions on an earlier version of the paper. This research is supported by the NSF of China (Grant No. 71562036),Project on Applied Basic Research in Yunnan province (2015FB142), Youth Leaders Project in Academic and Technical of Yunnan Province (2014HB009), and Yunnan provincial doctoral discipline construction planning (Applied Economics).

\section{REFERENCE}

[1] E. Fama, "The Behavior of Stock Market Prices," Journal of Bussness.1965,(1):34-105.J. Clerk Maxwell, A Treatise on Electricity and Magnetism, 3rd ed.,Oxford: Clarendon, vol. 2, pp. 68-73, 1892.

[2] E. Fama, "The cross-section of expected stock returns," Journal of Finance, vol. (6), pp. 427-465, 1992.

[3] J. Conrad and G. Kaul, "Time-Variation in Expected Retrens," Journal of Business, vol. (10), pp. 409-425, 1988.

[4] N.J. Sheridan, "Timan.Returns to Buying Winners and Selling Losers: Implications for Stock Market Efficiency," Journal of Finance, vol. (5), pp. 65-91, pp. 1993.

[5] M. Wang and J. Sun, "Stock Market Returns, Volatility and the Role of Investor Sentiment in China," Economic Research Journal, vol. (10), pp. 75-83, 2004. 